\title{
Morphologic assessment of mandibular anterior teeth root canal using CBCT
}

\author{
Sina Haghanifar ${ }^{1}$, Ehsan Moudi ${ }^{1}$, Ali Bijani ${ }^{2}$, Mohammad Kazemi Ghanbarabadi ${ }^{1}$
}

${ }^{1}$ Department of Oral and Maxillofacial Radiology, Faculty of Dentistry, Babol University of Medical sciences, Iran ${ }^{2}$ Social determinants of Health Research Center, Health Research Institute, Babol University of Medical Sciences, Babol, Iran

\author{
Correspondence: \\ kazemi_mhmd@yahoo.com \\ Tel.: + 981132291093 \\ Fax.: + 981132291094
}

Received: 26 May 2017

Accepted: 18 October 2017

Key words: Mandibular anterior teeth Apical foramen $\cdot$ Morphology $\cdot$ Root canal - Cone beam computed tomography.

\begin{abstract}
Objective. The aim of this study was to evaluate the number and morphological characteristics of the roots and root canals in mandibular anterior teeth, using cone beam computed tomography. Methods and materials. In this cross-sectional study, 1053 anterior mandibular teeth from 200 CBCT scans were evaluated. The teeth were completely developed and should have had no fillings in the root or crown. The teeth were investigated in terms of the number of roots and root canals, the location of the apical foramen, the distance of the apical foramen to the anatomical apex, root length, crown length, dilacerations and the type of canals according to Vertucci's classification. Results. $87.9 \%$ of teeth had one root canal and of all of the teeth, three canines $(0.3 \%)$ were found that had two roots. In $80.3 \%$ (n: 848 ) of cases the foramen apical location was central, then the buccal $(9.3 \%)$, lingual (3.9\%), distal (3.8\%), and mesial (2.7\%). The type of root canals, according to Vertucci's classification, with respect to prevalence, included type I (88.2\%), type III (8.1\%), type II (3.3\%), type V $(0.3 \%)$, and type VI $(0.1 \%)$, respectively. In terms of the characteristics investigated, bilateral symmetry was observed. Dilaceration was not seen in any of the teeth. Conclusion. The root canal morphology of mandibular anterior teeth has great diversity that may differ between different races, and should be considered by all dentists in order to achieve the best dental treatment.
\end{abstract}

\section{Introduction}

Knowing the anatomy of the tooth, the morphology of the root and its morphological differences is useful in most dental procedures, especially root canal therapy. Successful root canal treatment requires appropriate and complete cavity access, full biomechanical clearing of the root canal, effective and complete chemical debridement, and filling of the canals (1-6). To achieve these goals, the dentist should have complete knowledge of the morphology of the dental root and root canal, and their variations. Insufficient knowledge of the number of roots or root canals, and root canal type and morphology will lead to treatment failure. Normally, the root canal system of mandibular central and lateral teeth is similar and oval in shape in an axial section (wider buccolingually than mesiodiastally) (7). Previous studies have shown that a high percentage of mandibular anterior teeth have one root canal (1-4, 8-19). Often a dentinal bridge within the pulp space creates two canals within the sin- 
gle root.These two canals may merge together to form an apex in a single apical foramen, or may be separated from each other all the way to the end. Sometimes the inability to find the lingual root canal causes failure of endodontic treatment (3). Determining the root length also is an important factor in a successful root canal treatment because debridement and complete disinfection of the root canal is done without traumatizing the periapical tissue. Incorrect working length may lead to over instrumentation. Intraoral radiography is a common technique in determining root length during endodontic treatment. Sometimes the apical foramen opens in a position other than the apex to the lingual, buccal, mesial and distal openings. The buccal and lingual position of the apical foramen is not detected on intraoral radiography. The non-central position of the apical foramen can lead to incorrect assessment of root canal length and damage to the periapical tissue, and unsuccessful root canal treatment (20). Dilaceration is defined as a sudden change in the axial inclination of root, or between the crown and the root of a tooth. Awareness of the presence of this anomaly in the root can prevent root canal perforation and determine the best treatment plan leading to successful root canal therapy (21).

In previous studies, conventional X-ray techniques, root canal staining techniques, clearing technique, tooth sectioning and microscopic observation, etc. were used (3, $4,7,8,10,17,22-24)$. Although staining the root canal and clearing techniques are the gold standard for studying the morphology of the root canal, they are only performable on extracted teeth. Recently, the CBCT (Cone Beam Computed Tomography) technique has been used to study the morphology of the root canal. The benefits include non-invasiveness, its ability to be used clinically, and the bilateral study in the patient. Given that in CBCT images are displayed in three sagittal, axial, and coronal views, it helps clinicians to observe the three-dimensional morphology features $(6,24)$.

The aim of this study was to evaluate the morphology of the roots and root canal, the number of roots and root canals, the type of root canal (Vertucci's classification), the distance from the apical foramen to the anatomical apex, crown length, root length, dilacerations, and the location of the apical foramen, in mandibular anterior teeth.

\section{Methods and materials}

In this cross-sectional study, 1053 mandibular anterior teeth, related to $200 \mathrm{CBCTs}$, were selected from patients who referred to a private oral and maxillofacial radiology center during 2014-2016 for treatment purposes. Of 1053 mandibular anterior teeth, 317 were central, 371 lateral, and 365 were canines. $94(47 \%)$ of cases were male and $106(53 \%)$ were female, and the mean ages of the women and the men were $41.5 \pm 13.7$ and $47.3 \pm 13.3$ years, respectively. Selected patients had to have at least one tooth in the anterior mandible; the teeth had to be completely developed and had to have no fillings in the root and crown, no cast metal post inside the canal, and no apical lesions. The CBCT images had to be of a desirable quality, and with no artifacts.

All images were prepared by Cranex3D (Soredex/Helsinki/Finland) and the scanning parameters included: $89 \mathrm{kvp}, 6 \mathrm{~mA}$, field of view: $6 \times 8 \mathrm{~cm}$, and voxel size: $0.2 \mathrm{~mm}$. Also, Ondemand 3D Dental software was used for processing images. The teeth were investigated in axial, coronal, and sagittal sections, with a thickness of $0.1 \mathrm{~mm}$. The observer used all the software features, such as zooming, and changes to contrast and brightness.

Mandibular anterior teeth were investigated in terms of the number of roots and root canals, the location of the apical foramen (Figure 1), the distance of the apical 


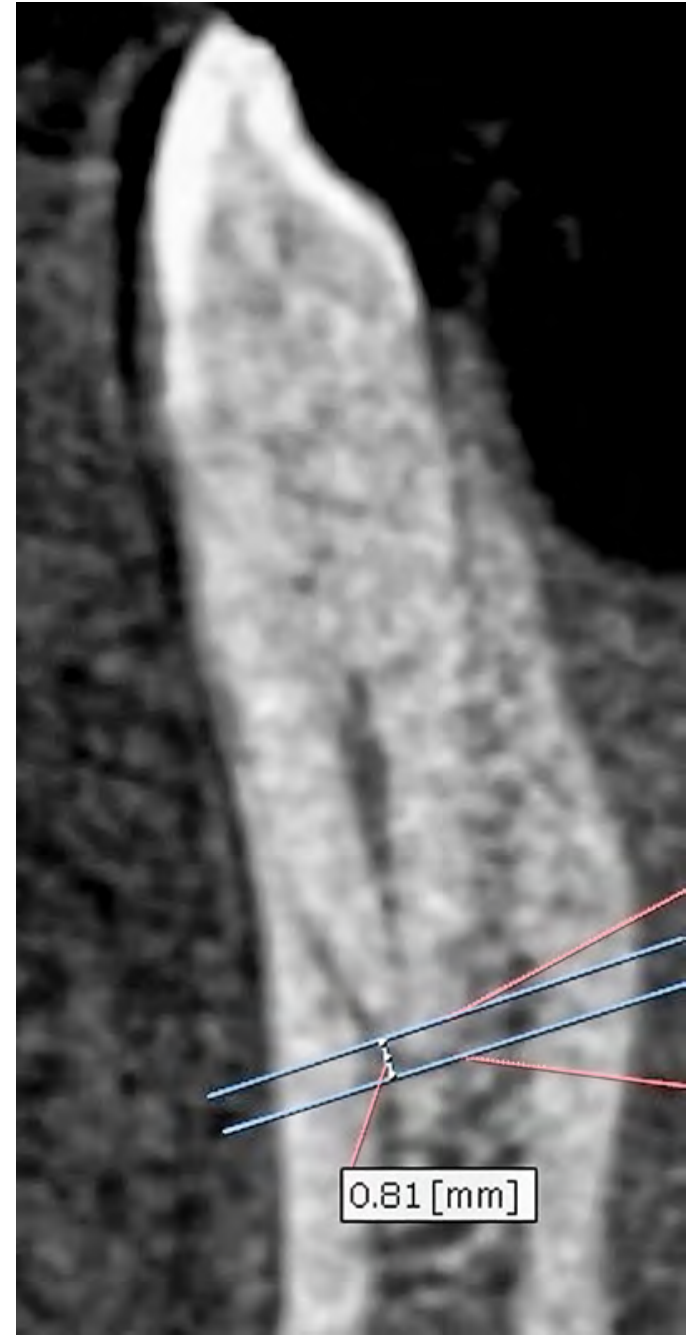

Figure 1 Illustration of foramen apical and apex and distance from foramen apical to apex.

foramen to the anatomical apex (Figure 1), root length, crown length, the type of canals according to Vertucci's classification and dilaceration. The root length was measured from the CEJ to the tooth's apex and crown length from the CEJ (Cemento Enamel Junction) to the incisal edge (Figure 2). Vertucci type I was considered single-canal and Vertucci type VIII was considered to be three canals (Figure 3).

\section{Statistical analysis}

All the data were analyzed by SPSS 17 software and statistical tests including Student's t-test,

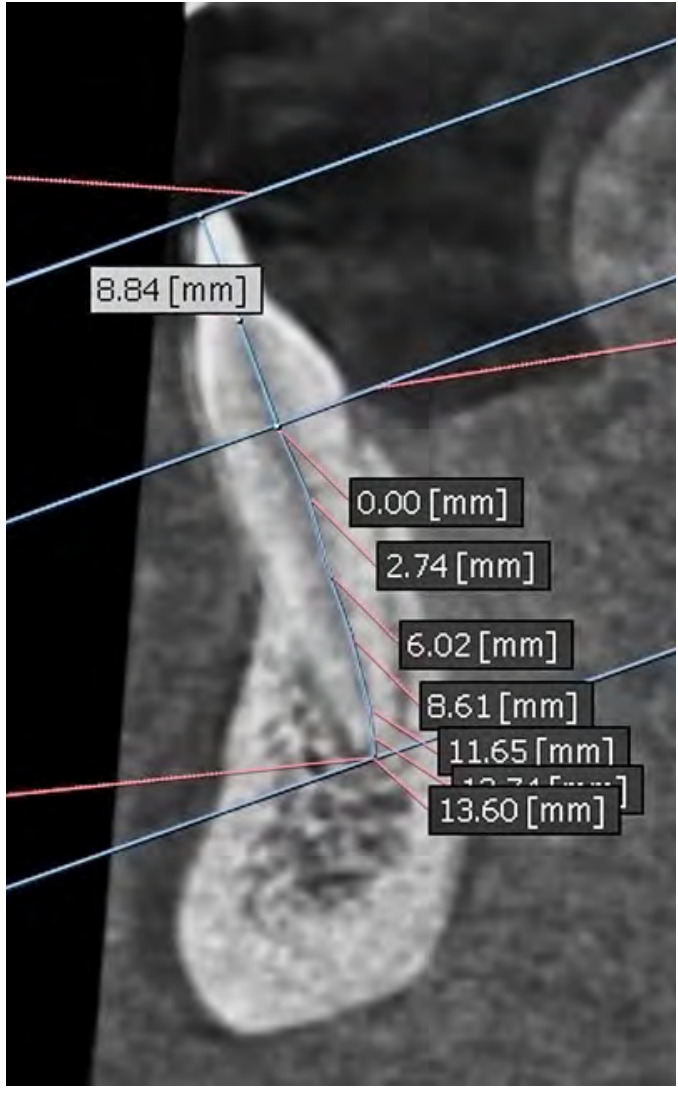

Figure 2 Measurement of crown and root length.

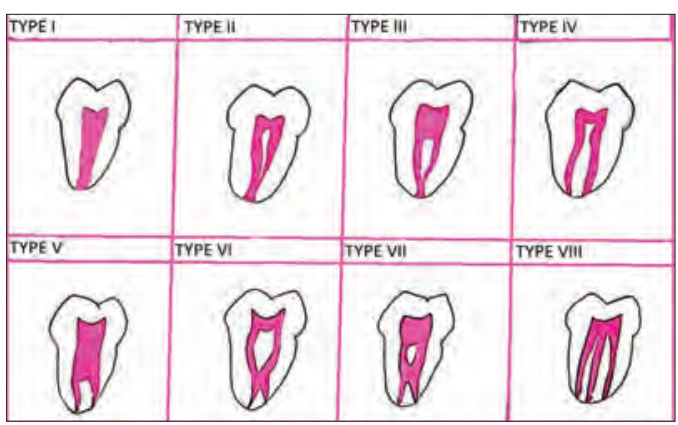

Figure 3 Vertucci classifications.

Pearson correlation, chi-square test and Fisher test. $\mathrm{P}<0.05$ was considered significant.

\section{Results}

$928(87.9 \%)$ of the teeth had one root canal, and, accordingly, the highest percentage of single-canal teeth were canine, and the highest percentage of two root canals was related 


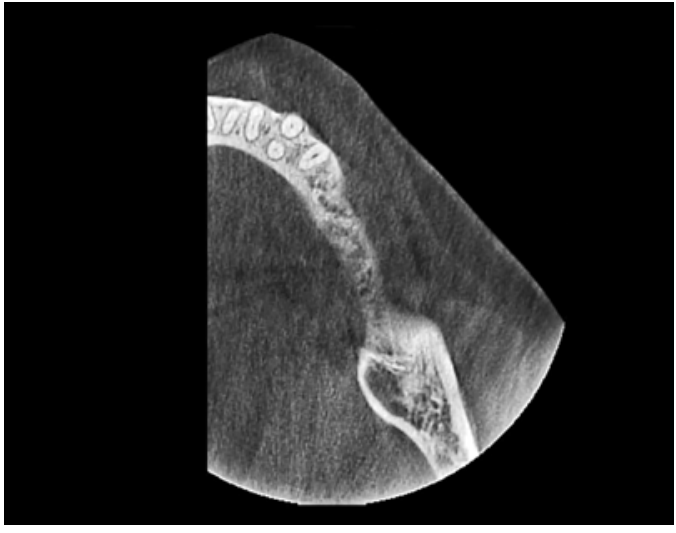

Figure 4 Mandibular canine with two roots.

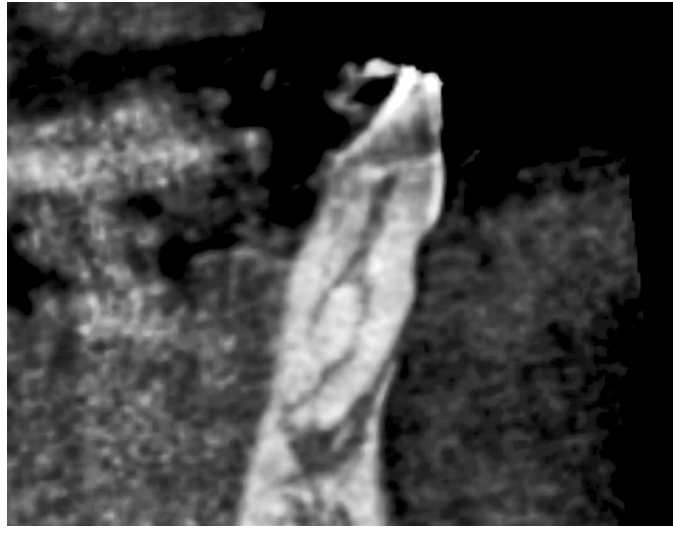

Figure 5 Type VII by Vertucci's classification.

Table 1 Distribution of the number of mandibular anterior teeth root canals in terms of sex

\begin{tabular}{|c|c|c|c|c|c|}
\hline \multirow{3}{*}{ Tooth } & \multirow{3}{*}{ Sex } & \multicolumn{2}{|l|}{ Root canals } & \multirow{3}{*}{$x^{2}$} & \multirow{3}{*}{$p$} \\
\hline & & Single canal & Two canals & & \\
\hline & & n (\%) & n (\%) & & \\
\hline \multirow{2}{*}{ Central } & Men & $117(80.1)$ & 29 (19.9) & \multirow{2}{*}{1.92} & \multirow{2}{*}{0.166} \\
\hline & Women & $147(86)$ & $24(14)$ & & \\
\hline \multirow{2}{*}{ Lateral } & Men & $138(80.2)$ & 34 (19.8) & \multirow{2}{*}{0.77} & \multirow{2}{*}{0.186} \\
\hline & Women & $170(85.4)$ & 29 (14.6) & & \\
\hline \multirow{2}{*}{ Canine } & Men & $159(96.4)$ & $6(3.6)$ & \multirow{2}{*}{0.13} & \multirow{2}{*}{0.715} \\
\hline & Women & 197 (97) & $6(3)$ & & \\
\hline
\end{tabular}

Table 2 Distribution of different types of Vertucci's classification in mandibular anterior teeth on both sides of the mandible

\begin{tabular}{llll}
\hline \multirow{2}{*}{ Tooth } & \multirow{2}{*}{ Side } & \multicolumn{2}{l}{ Types of Vertucci's classification } \\
\cline { 2 - 4 } Central & Right & $137(86.2)$ & II, III, V, VII n (\%) \\
\cline { 2 - 4 } & Left & $127(80.4)$ & $22(13.8)$ \\
\hline \multirow{2}{*}{ Lateral } & Right & $156(83.9)$ & $31(19.6)$ \\
\cline { 2 - 4 } & Left & $152(82.2)$ & $30(16.1)$ \\
\hline \multirow{2}{*}{ Canine } & Right & $180(97.8)$ & $33(17.8)$ \\
\cline { 2 - 4 } & Left & $179(97.3)$ & $4(2.2)$ \\
\hline \multirow{2}{*}{ Total } & Right & $473(89.4)$ & $5(2.7)$ \\
\cline { 2 - 4 } & Left & $458(86.9)$ & $56(10.6)$ \\
\hline
\end{tabular}

$\mathrm{p}$ value refers to Fisher's test.

Table 3 Apical foramen location in terms of sex

\begin{tabular}{|c|c|c|c|c|c|}
\hline \multirow{2}{*}{ Sex } & \multicolumn{5}{|c|}{ Apical foramen location } \\
\hline & Central & Mesial & Distal & Buccal & Lingual \\
\hline Man n (\%) & $388(80.3)$ & $21(4.3)$ & $24(5)$ & $37(7.7)$ & $13(2.7)$ \\
\hline Woman n (\%) & $460(80.3)$ & $8(1.4)$ & $16(2.8)$ & $61(10.6)$ & $28(4.9)$ \\
\hline Total n (\%) & $848(80.3)$ & $29(2.7)$ & $40(3.8)$ & $98(9.3)$ & $41(3.9)$ \\
\hline
\end{tabular}

$x^{2}=17.36 ; p=0.002$. 
Table 4 Distribution of mean length of crown and root in terms of sex and sides of the mandible in the mandibular anterior teeth

\begin{tabular}{|c|c|c|c|c|c|c|c|}
\hline Tooth & Sex & $\mathrm{N}$ & Sides & Length (mm) & Mean $\pm S D$ & $\mathrm{t}$ & $\mathrm{p}$ \\
\hline \multirow{8}{*}{ Central } & \multirow{4}{*}{ Man } & 74 & Right & \multirow{2}{*}{ Crown length } & $6.77 \pm 1.53$ & \multirow{2}{*}{-1.01} & \multirow{2}{*}{0.312} \\
\hline & & 72 & Left & & $7.03 \pm 1.58$ & & \\
\hline & & 74 & Right & \multirow{2}{*}{ Root length } & $13.8 \pm 1.55$ & \multirow{2}{*}{-0.39} & \multirow{2}{*}{0.696} \\
\hline & & 72 & Left & & $13.9 \pm 1.63$ & & \\
\hline & \multirow{4}{*}{ Woman } & 85 & Right & \multirow{2}{*}{ Crown length } & $7.25 \pm 1.00$ & \multirow{2}{*}{-0.30} & \multirow{2}{*}{0.764} \\
\hline & & 86 & Left & & $7.3 \pm 0.99$ & & \\
\hline & & 85 & Right & \multirow{2}{*}{ Root length } & $12.7 \pm 1.88$ & \multirow{2}{*}{-0.51} & \multirow{2}{*}{0.610} \\
\hline & & 86 & Left & & $12.8 \pm 1.50$ & & \\
\hline \multirow{8}{*}{ Lateral } & \multirow{4}{*}{ Man } & 88 & Right & \multirow{2}{*}{ Crown length } & $7.41 \pm 1.51$ & \multirow{2}{*}{-0.47} & \multirow{2}{*}{0.637} \\
\hline & & 84 & Left & & $7.52 \pm 1.56$ & & \\
\hline & & 88 & Right & \multirow{2}{*}{ Root length } & $14.5 \pm 1.66$ & \multirow{2}{*}{-1.43} & \multirow{2}{*}{0.154} \\
\hline & & 84 & Left & & $14.96 \pm 1.81$ & & \\
\hline & \multirow{4}{*}{ Woman } & 98 & Right & \multirow{2}{*}{ Crown length } & $7.57 \pm 1.08$ & \multirow{2}{*}{-0.15} & \multirow{2}{*}{0.883} \\
\hline & & 101 & Left & & $7.59 \pm 0.98$ & & \\
\hline & & 98 & Right & \multirow{2}{*}{ Root length } & $14.13 \pm 1.58$ & \multirow{2}{*}{-1.19} & \multirow{2}{*}{0.236} \\
\hline & & 101 & Left & & $14.4 \pm 1.63$ & & \\
\hline \multirow{8}{*}{ Canine } & \multirow{4}{*}{ Man } & 84 & Right & \multirow{2}{*}{ Crown length } & $8.49 \pm 1.55$ & 11 & (2) \\
\hline & & 81 & Left & & $8.46 \pm 1.56$ & 0.11 & 0.910 \\
\hline & & 84 & Right & Doctlangth & $16.82 \pm 1.95$ & 060 & 007 \\
\hline & & 81 & Left & noot iengan & $17.04 \pm 2.11$ & -0.09 & 0.492 \\
\hline & & 100 & Right & 5 & $8.12 \pm 1.14$ & בת & ل רחم: \\
\hline & Whmor & 103 & Left & crovniengan & $8.16 \pm 0.98$ & -0.25 & 0.002 \\
\hline & vroman & 100 & Right & Routlonath & $16.04 \pm 1.85$ & 075 & רז0 \\
\hline & & 103 & Left & noor iengan & $15.85 \pm 1.83$ & 0.13 & 0.452 \\
\hline
\end{tabular}

to lateral teeth ( $\mathrm{p}$-value $>0.05)$. There was no significant difference between men and women or between the right and left sides of the mandible, regarding the number of canals (Table 1).

Of all the teeth, three canine $(0.3 \%)$ were found that had two roots (Figure 4). The type of root canals, according to Vertucci's classification, with respect to prevalence, included type I (88.2\%), type III (8.1\%), type II (3.3\%), type V $(0.3 \%)$, and type VII $(0.1 \%)$, (Figure 5) respectively. Canine teeth were less likely to have Vertucci type II and type
III; and type II and type III were observed more in central and lateral teeth. In terms of Vertucci's classification, there were no differences between the right and left mandible (Table 2).

The location of the apical foramen, according to the most frequent finding, was central (80.3\%), then buccal (9.3\%), lingual (3.9\%), distal (3.8\%), and mesial (2.7\%), respectively. There was a significant difference between women and men (Table 3). The mean distance of the apical foramen from the anatomical apex was $0.12 \pm 0.36 \mathrm{~mm}$, the 
Table 5 Length of crown, length of root and distance from apical foramen to apex in two age groups in male and female

\begin{tabular}{|c|c|c|c|c|c|}
\hline Sex & Age (y) & Measurements & Mean $\pm S D$ & $\mathrm{t}$ & $\mathrm{p}$ \\
\hline \multirow{6}{*}{ Male } & $<50$ & \multirow{2}{*}{ Length of crown } & $8.11 \pm 1.43$ & \multirow{2}{*}{-0.83} & \multirow{2}{*}{$<0.001$} \\
\hline & $>=50$ & & $6.96 \pm 1.75$ & & \\
\hline & $<50$ & \multirow{2}{*}{ Length of root } & $15.25 \pm 2.26$ & \multirow{2}{*}{0.256} & \multirow{2}{*}{0.799} \\
\hline & $>=50$ & & $15.20 \pm 2.12$ & & \\
\hline & $<50$ & \multirow{2}{*}{ Distance* } & $0.12 \pm 0.36$ & \multirow{2}{*}{-0.457} & \multirow{2}{*}{0.648} \\
\hline & $>=50$ & & $0.13 \pm 0.40$ & & \\
\hline \multirow{6}{*}{ Female } & $<50$ & \multirow{2}{*}{ Length of crown } & $8.00 \pm 1.03$ & \multirow{2}{*}{8.801} & \multirow{2}{*}{$<0,001$} \\
\hline & $>=50$ & & $7.23 \pm 1.02$ & & \\
\hline & $<50$ & \multirow{2}{*}{ Length of root } & $14.50 \pm 2.21$ & \multirow{2}{*}{1.071} & \multirow{2}{*}{0.285} \\
\hline & $>=50$ & & $14.31 \pm 2.01$ & & \\
\hline & $<50$ & \multirow{2}{*}{ Distance* } & $0.14 \pm 0.37$ & \multirow{2}{*}{1.130} & \multirow{2}{*}{0.259} \\
\hline & $>=50$ & & $0.10 \pm 0.31$ & & \\
\hline
\end{tabular}

*From apical foramen to apex.

mean crown length was $7.6 \pm 1.38 \mathrm{~mm}$, and mean root length was $14.7 \pm 2.2 \mathrm{~mm}$. The mean crown and root length of central teeth was $7.1 \pm 1.29$ and $13.2 \pm 1.72$ respectively and for lateral teeth $7.5 \pm 1.28$ and $14.5 \pm 1.69$ respectively, where canine teeth, with mean crown length of $8.2 \pm 1.38 \mathrm{~mm}$, and mean root length of $16.3 \pm 1.98 \mathrm{~mm}$, had the longest crowns and roots of the mandibular anterior teeth ( $\mathrm{p}$-value $<0.05)$. Women had longer crowns ( $p$-value $=0.001)$ and men had longer roots ( $\mathrm{p}$-value $=0.801$ ) (Table 4). With increasing age, the crown length decreased $(r=-0.313, p=0.000)$, but the root length $(\mathrm{r}=0.021, \mathrm{p}=0.495)$ and the distance of the anatomical apex from the apical foramen $(\mathrm{r}=-0.016, \mathrm{p}=0.594)$ did not change (Table 5). Crown and root lengths and the distance of the anatomical apex from the apical foramen did not differ between the two sides of the mandible, and no dilaceration was seen in any of the teeth.

\section{Discussion}

In this study, $87.9 \%$ of the mandibular anterior teeth were single-canal and the dominance of single-canal in all previous studies confirms our findings, although the proportion differs, which may be due to racial differences (1-4, 8-19). Aminsobhani et al. (1) reported that $71.7 \%$ of mandibular anterior teeth had a single root canal. Vertucci et al. (17) reported that $27.5 \%$ of the incisor teeth had two root canals. Boruah et al. studied the mandibular incisors by the clearing technique and Kamtane et al. $(10,12)$ studied the mandibular incisors by CBCT, and reported that $64 \%$ of teeth had one root canal. Zhao et al. (18) studied a Chinese population and reported that $6.7 \%$ of the central, $16.7 \%$ of the lateral, and $3 \%$ of canine teeth had two root canals. Zhegyan et al. (19) reported that $3.8 \%$ of the central, $10.6 \%$ of the lateral, and $2.4 \%$ of the canine teeth had more than one root canal.

In this investigation, all incisors were single-rooted and of all of the teeth, three canines $(0.3 \%)$ were found that had two roots. In most studies, incisors were found to be single-rooted and two roots were more prevalent in canine teeth $(1,11-13,15,18$, 19). In Kayaoglu's study (13), all mandibular central teeth, and $99.9 \%$ of the laterals were single-rooted, and $3.1 \%$ of the canines had two roots (13). Zhegyan et al. (19) showed 
that all central teeth were single-rooted and $0.3 \%$ of mandibular lateral teeth and $0.8 \%$ of canine teeth had two roots (19). In a study by Han et al. (11) on a Chinese population, it was found that all mandibular incisors were single-rooted, and $1.32 \%$ of canines were double rooted (11). Rahimi et al. (4) reported that all incisors were single-rooted and $12.08 \%$ of the canines were double rooted.

The present study showed the prevalence of double root canals in the mandibular lateral (17\%), and central (16.7\%) teeth was more than in the canine teeth $(9.4 \%)$ (pvalue $>0.05$ ), but no significant differences were observed between men and women, or between the two sides of the mandible. In a study by Liu et al. (15) on Chinese populations, the frequency of double root canals was higher in lateral than in central teeth, and the frequency of double root canals was slightly higher in men than in women. Han et al. (11) reported that the prevalence of double root canals was higher in mandibular lateral teeth than in canine and central teeth Lin et al. (14) study showed that lateral incisor teeth tended to have more double root canals. Kayaoglu et al. (13) reported that, in a Turkish population, double root canals were observed more in lateral teeth, and double root canal teeth were observed in bilateral symmetry in the mandible, and also bilateral symmetry of the jaw was observed for all the studied characteristics. Arslan et al. (2) reported greater anatomical complexity of canals in the mandibular incisors in men than in women, while no such difference was observed between male and female participants in the characteristics studied in the present study.

The results of this study indicated that Vertucci type I (88.2\%) had the highest prevalence, then type III (8.1\%), type II (3.3\%), type V $(0.3 \%)$ and type VII $(0.1 \%)$, respectively. In all studies, Vertucci type I had the highest prevalence, as in our study $(1,8,9,11-16,18,19)$. The study by Lin et al.
(14) showed that, among double root canals, Vertucci type III was most prevalent. Sobhani et al. (1) reported that the prevalence of different types of canals, related to Vertucci classification, was types I, II, IV, III, and V, respectively. Altunsoy et al. (9) reported that Vertucci type I had the greatest prevalence among mandibular incisors, and type $\mathrm{V}$ had the greatest prevalence in double root canals. In the study conducted by Rahimi et al. (4) the greatest prevalence were types I, II, III, and IV, respectively. Silva et al. (25) determined the prevalence of different types of canals as types I, III, and V, respectively. Zhao et al. (18) evaluated the prevalence of different types of canals and reported types I, III, V, VII, and IV, respectively These differences may be due to the different populations studied. The mean crown length of all evaluated mandibular anterior teeth was $7.6 \pm 1.3 \mathrm{~mm}$, and the mean root length was $14.7 \pm 2.2 \mathrm{~mm}$. Canine teeth with a mean crown length of $8.2 \pm 1.3 \mathrm{~mm}$ and mean root length of $16.3 \pm 1.9 \mathrm{~mm}$ had the longest crown and roots of the anterior mandibular teeth. Women had longer crowns and men had longer roots. Soleymani et al. (5) reported canine root length of $15.53 \mathrm{~mm}$, and root length was greater in men than in women.

The location of the apical foramen was central (80.3\%), buccal (9.3\%), lingual (3.9\%), distal (3.8\%), and mesial (2.7\%), respectively. Soleymani et al. (5), in a study on canine teeth, showed that in $68.3 \%$ of cases the apical foramen was in the central location. Boruah et al. (10) evaluated mandibular incisors and showed that the foramen apical location in $47.2 \%$ was central, $34.3 \%$ buccal, $13.3 \%$ lingual, and $5 \%$ proximal. These differences may be due to the method of studying the teeth, the population and racial differences. Boruah et al. (10) evaluated extracted teeth by the clearing method, and using a magnifying glass with $5 \mathrm{x}$ magnification.

No dilacerations were observed in any of the studied mandibular anterior teeth. Previ- 
ous studies have also reported a very small incidence of dilaceration in mandibular anterior teeth $(21,26)$. Nabavizade et al.(21) determined of all teeth, dilaceration was found in the second mandible molars, the first maxillary molar, and the first mandibular molar, respectively, but not in mandibular anterior teeth. Hamasha et al. (26) examined 4655 dental x-rays; mandibular anterior teeth had the lowest prevalence of dilaceration of all teeth, with a prevalence of only $1 \%$.

\section{Conclusion}

The findings of this study indicate that most anterior mandibular teeth have a single root and single root canal, and there is no significant morphological difference between different individuals, but the root canal morphology of the anterior mandibular teeth may be extremely diverse, and may differ between different races, and this should be considered by all dentists in order to achieve the best dental treatment. Although CBCT is very helpful in determining root canal morphological characteristics, it is not recommended for everyone.

\section{What is already known on this topic}

In mandibular anterior teeth, wide ranges of morphological features are observed, where features such as single-canal, single-root, type I Vertucci and others, have a high percentage of similarity between different individuals. However, slight differences may affect root canal therapy. So far, various ex vivo methods have been used to assess this feature, but CBCT is a new and clinical method. CBCT can help the technician to see three-dimensional images of morphological features the teeth.

\section{What this study adds}

Although most individuals have similar morphological features, the percentage of similarity between individuals differs. Bilateral symmetry of different morphological features of teeth in a jaw can be assessed using CBCT. With increasing knowledge of the morphological features of teeth and bilateral symmetry of the jaw, the best treatment can be given to prevent the failure of root canal therapy.

Acknowledgements: This article presented the results of a research project at Babol University of Medical
Sciences (by Grant No: 954218). The funding and support of the Research Deputy of Babol University of Medical Sciences is highly appreciated.

Authors' contributions: Conception and design: $\mathrm{SH}$ and MKG; Acquisition, analysis and interpretation of data: MKG, AB and SH; Drafting the article: MKG; Revising it critically for important intellectual content: SH and EM; Approved final version of the manuscript: $\mathrm{SH}, \mathrm{EM}, \mathrm{AB}$ and $\mathrm{MKG}$.

Conflict of interest: The authors declare that they have no conflict of interest.

\section{References}

1. Aminsobhani M, Sadegh M, Meraji N, Razmi $\mathrm{H}$, Kharazifard MJ. Evaluation of the root and canal morphology of mandibular permanent anterior teeth in an Iranian population by conebeam computed tomography. J Dent (Tehran). 2013;10(4):358-66.

2. Arslan H, Ertas H, Ertas ET, Kalabalık F, Saygılı G, Capar ID. Evaluating root canal configuration of mandibular incisors with cone-beam computed tomography in a Turkish population. JDS. 2015;10(4):359-64.

3. Assadian H, Dabbaghi A, Gooran M, Eftekhar B, Sharifi S, Shams N, et al. Accuracy of CBCT, Digital Radiography and Cross-Sectioning for the Evaluation of Mandibular Incisor Root Canals. Iran Endod J. 2016;11(2):106-10.

4. Rahimi S, Milani AS, Shahi S, Sergiz Y, Nezafati S, Lotfi M. Prevalence of two root canals in human mandibular anterior teeth in an Iranian population. Indian J Dent Res. 2013;24(2):234-6.

5. Soleymani A, Namaryan N, Moudi E, Gholinia A. Root Canal Morphology of Mandibular Canine in an Iranian Population: A CBCT Assessment. Iran Endod J. 2017;12(1):78-82.

6. Yang H, Tian C, Li G, Yang L, Han X, Wang Y. A cone-beam computed tomography study of the root canal morphology of mandibular first premolars and the location of root canal orifices and apical foramina in a Chinese subpopulation. J Endod. 2013;39(4):435-8.

7. Huang DM, Hao YQ, Luo SG, Jia LH, Zhou XD. Morphology of cross-sectioned root canal in Chinese mandibular permanent incisors [in Chinese]. Sichuan Da Xue Xue Bao Yi Xue Ban. 2006;37(6):916-8.

8. Al-Qudah AA, Awawdeh LA. Root canal morphology of mandibular incisors in a Jordanian population. Int Endod J. 2006;39(11):873-7. 
9. Altunsoy M, Ok E, Nur BG, Aglarci OS, Gungor E, Colak M. A cone-beam computed tomography study of the root canal morphology of anterior teeth in a Turkish population. Eur J Dent. 2014;8(3):302-6.

10. Boruah LC, Bhuyan AC. Morphologic characteristics of root canal of mandibular incisors in North-East Indian population: An in vitro study. J Conserv Dent. 2011;14(4):346-50.

11. Han T, Ma Y, Yang L, Chen X, Zhang X, Wang Y. A study of the root canal morphology of mandibular anterior teeth using cone-beam computed tomography in a Chinese subpopulation. J Endod. 2014;40(9):1309-14.

12. Kamtane S, Ghodke M. Morphology of Mandibular Incisors: A Study on CBCT. Pol J Radiol. 2016;81:15-6.

13. Kayaoglu G, Peker I, Gumusok M, Sarikir C, Kayadugun A, Ucok O. Root and canal symmetry in the mandibular anterior teeth of patients attending a dental clinic: CBCT study. Braz Oral Res. 2015;29.

14. Lin Z, Hu Q, Wang T, Ge J, Liu S, Zhu M, et al. Use of CBCT to investigate the root canal morphology of mandibular incisors. Surg Radiol Anat. 2014;36(9):877-82.

15. Liu J, Luo J, Dou L, Yang D. CBCT study of root and canal morphology of permanent mandibular incisors in a Chinese population. Acta Odontol Scand. 2014;72(1):26-30.

16. Miyashita M, Kasahara E, Yasuda E, Yamamoto A, Sekizawa T. Root canal system of the mandibular incisor. J Endod. 1997;23(8):479-84.

17. Vertucci FJ. Root canal anatomy of the human permanent teeth. Oral Surg Oral Med Oral Pathol. 1984;58(5):589-99.

18. Zhao Y, Dong YT, Wang XY, Wang ZH, Li G, Liu $\mathrm{MQ}$, et al. Cone-beam computed tomography analysis of root canal configuration of 4674 mandibular anterior teeth [in Chinese]. Beijing da xue xue bao Yi xue ban. 2014;46(1):95-9.

19. Zhengyan Y, Keke L, Fei W, Yueheng L, Zhi Z. Cone-beam computed tomography study of the root and canal morphology of mandibular permanent anterior teeth in a Chongqing population. Ther Clin Risk Manag. 2016;12:19-25.

20. Bahrololoomi Z, Soleymani AA, Modaresi J, Imanian M, Lotfian M. Accuracy of an Electronic Apex Locator for Working Length Determination in Primary Anterior Teeth. J Dent. 2015;12(4):243-8.

21. Nabavizadeh M, Sedigh Shamsi M, Moazami F, Abbaszadegan A. Prevalence of root dilaceration in adult patients referred to shiraz dental school (2005-2010). J Dent. 2013;14(4):160-4.

22. Kartal N, Yanikoglu FC. Root canal morphology of mandibular incisors. J Endod. 1992;18(11):562-4.

23. Morfis A, Sylaras SN, Georgopoulou M, Kernani M, Prountzos F. Study of the apices of human permanent teeth with the use of a scanning electron microscope. Oral Surg Oral Med Oral Pathol. 1994;77(2):172-6.

24. Wen SH, Lin ZT, Zhu M, Ge JY, Wang TM. Comparative study of root canal morphology of mandibular incisors by cone-beam CT and canal staining and clearing technique [in Chinese]. Shanghai kou qiang yi xue. 2016;25(1):6-10.

25. Silva EJ, Castro RW, Nejaim Y, Silva AI, HaiterNeto F, Silberman A, et al. Evaluation of root canal configuration of maxillary and mandibular anterior teeth using cone beam computed tomography: An in-vivo study. Quintessence Int. 2016;47(1):19-24.

26. Hamasha AA, Al-Khateeb T, Darwazeh A. Prevalence of dilaceration in Jordanian adults. Int Endod J. 2002;35(11):910-2. 